\title{
Analysis of a Hybrid System for Decentralized Power Generation
}

\author{
H. Hinz
}

\begin{abstract}
Traditionally a centralized power generation based on fossil fuels is common. To meet the greenhouse targets a transition to low carbon power generation is required. This could be achieved either by nuclear or renewable energy. Due to the concerns regarding nuclear safety and the problematic disposal of long live radioactive waste many countries move towards renewable energies. Thus a change to a decentralized power generation will occur. The objective of this paper is to describe the development of a hybrid system for a decentralized power generation. It is shown that the proposed design of a combined heat and power plant and a photovoltaic array including an electric energy storage device will establish a future oriented technology. A method is introduced which enables the study and optimization of the power management.
\end{abstract}

Index Terms-Decentralized power generation, lithium-ion battery, modeling, photovoltaic.

\section{INTRODUCTION}

As a consequence of the Fukushima reactor catastrophe in the year 2011 the German government has decided an accelerated phasing out of nuclear energy. Up to 2022 a gradual decommissioning of nuclear power plants will take place. Thus the demand for the integration of renewable energy is obviously. In Germany currently one can observe an ongoing installation of onshore and large scale offshore wind farms as well as an increase of installed photovoltaic plants [1], [2]. This leads to a shift towards decentralized power generation. In the small town Kelsterbach located in the German Frankfurt/Rhine-Main metropolitan region with a total population of around 3.5 million a forward-looking approach of a decentralized power generation is currently installed. The system consists of a combined heat and power plant (CHP) which provides a residential neighborhood with thermal and electrical power. In case of conventional CHP the consumers are supplied with heat together with a peak load boiler to cover the total thermal power demand. In addition a certain amount of electrical power is provided. During periods of heavy consumption additional electrical power is provided by the public grid. The aim of the proposed system is to establish an independent power supply. Therefor in the decentralized power generation a photovoltaic system (PV) is integrated. Due to the fluctuation of the solar power an electric energy storage device is required.

Manuscript received September 25, 2013; revised January 14, 2014. This work was supported in part by the Hessen State Ministry of Higher Education, Research and the Arts, Grant title "Research for the real world 2012".

H. Hinz is with the Faculty of Computer Science and Engineering, University of Applied Sciences Frankfurt, Nibelungenplatz 1, Frankfurt D-60318 Germany (e-mail: hhinz@fb2.fh-frankfurt.de).

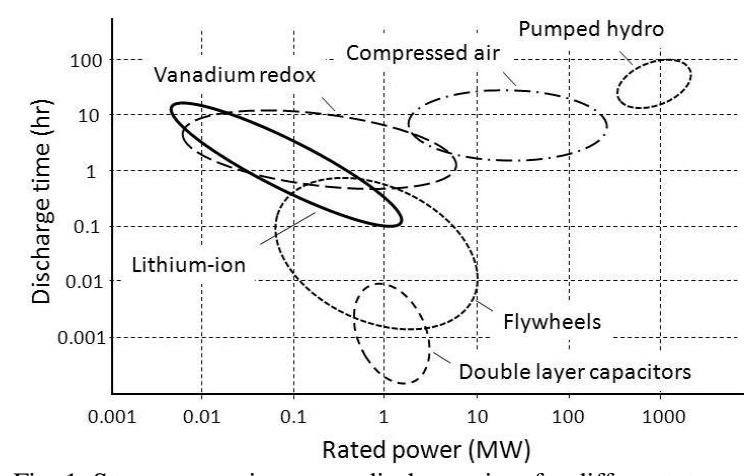

Fig. 1. Storage capacity versus discharge time for different storage technologies (Figure adapted from [4]).

Fig. 1 gives a general overview on different kinds of storage systems in dependence on the rated power and discharge time [3], [4]. For photovoltaic applications in the medium power range lithium-ion batteries seems to be the most promising solution. Hence an energy storage system which consists of a lithium-ion pack is used for the proposed application. To date no sufficient experiences exist on the operation of PV systems and lithium-ion batteries. Recently published research reports deal with different topics regarding battery storage technologies. In [5] PV hybrid systems in the power range up to $10 \mathrm{~kW}$ for single residential houses are analyzed, in [6] the integration of decentralized storage systems in the public grid is investigated. Other research projects can be found in [7]-[11]. However no validated results for a decentralized hybrid power generation in the medium power range are known so far. Thus the goal of the presented research study, which is conducted in cooperation with Süwag Renewable Energy GmbH in Frankfurt, is to find an optimized operation strategy and power management which ensures to meet the predicted annual $\mathrm{CO} 2$ savings of approximately 430 tons per year.

\section{SYSTEM TOPOLOGY}

Fig. 2 illustrates the residential neighborhood which consists of 180 town houses. The housing complex was built by Deutsche Reihenhaus AG, a German building enterprise.

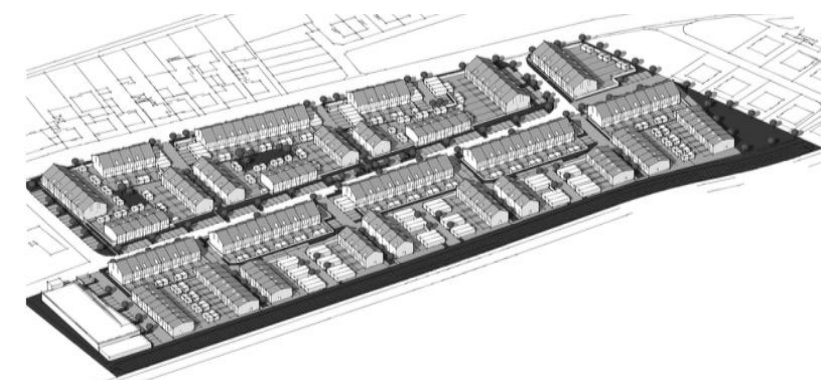

Fig. 2. Residential neighborhood (image courtesy of Deutsche Reihenhaus). 
The simplified topology of the proposed hybrid decentralized power generation is shown in Fig. 3. The CHP consists of one module with a rated electrical power of $P_{e l, C H P, N}=50 \mathrm{~kW}$ and thermal power of $P_{t h, C H P, N}=81 \mathrm{~kW}$. The corresponding efficiencies are $\eta_{e l}=34.5 \%$ and $\eta_{t h}=55.9 \%$, the total efficiency is $\eta_{\text {total }}=90.3 \%$. The thermal power of the installed peak load boiler is $895 \mathrm{~kW}$.

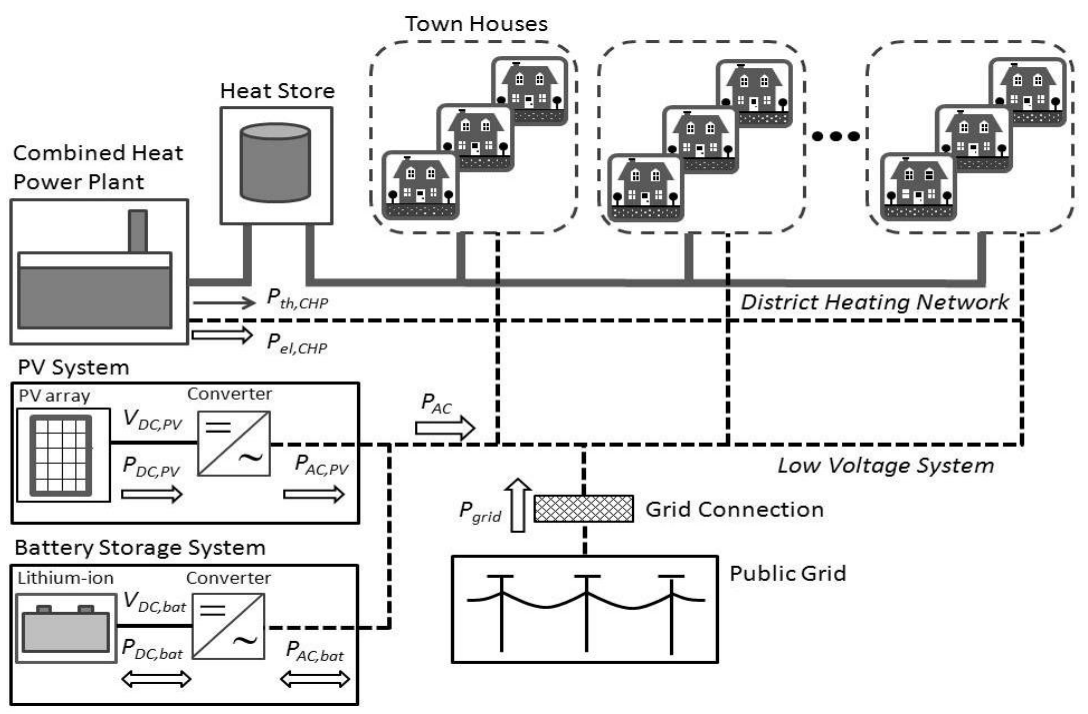

Fig. 3. System overview

The CHP is used to charge the heat storage tank which supplies the households with thermal power via a district heating network (solid line). Electrical power $P_{e l, C H P}$ is transmitted via a $400 \mathrm{~V} / 50 \mathrm{~Hz}$ low-voltage mains network (dashed line).

Fig. 4 shows the technical room of the plant. To establish an independent power supply a PV system with a projected peak power of $70 \mathrm{~kW}_{\mathrm{P}}$ will be integrated. As described above a lithium-ion battery with a projected nominal power of 100 $\mathrm{kW}$ is used to compensate the fluctuating solar power. The DC voltage on the PV panel output $V_{D C, P V}$ varies with the solar module temperature $T$ and the solar irradiation $S$, the DC voltage on the output terminal of the battery $V_{D C, B a t}$ varies with the state of charge (SOC). Therefor the PV panel and the battery can only be linked together by individual converters which convert the DC power, $P_{D C, P V}$ and $P_{D C, b a t}$, into the AC power for the voltage mains network, $P_{A C}=P_{A C, P V}+P_{A C, \text { bat }}$. To ensure a charge and discharge of the battery for the storage system a bidirectional converter is used, the converter of the PV system is unidirectional.

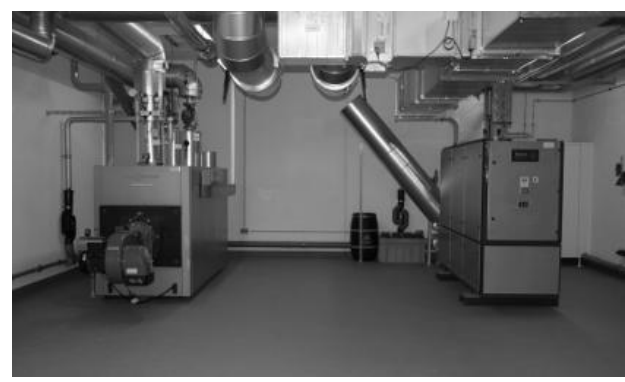

Fig. 4. Technical room of the combined heat and power plant (picture courtesy of Süwag Renewable Energy).

If an optimized power management is implemented the complete power demand of the consumers $P_{e l}$ is covered by the electrical power of the CHP $\left(P_{e l, C H P}\right)$ and the PV and battery system $\left(P_{A C}\right), P_{e l}=P_{e l, C H P}+P_{A C}$. In this way no power from the public grid is required, $P_{\text {grid }}=0$.

Due to the complexity of this topology and the insufficient experiences of hybrid systems a detailed analysis of the operational behavior is required. In this research project a simulation model is suggested which allows studying the steady state and dynamic behavior of each subsystem and its interactions. With the model based development in a first step control algorithm can be tested in the simulation.

In a second step these control algorithm can be implemented in the real system to establish an optimized power management.

In the next section the modeling approach is described.

\section{COMBInEd HeAt AND POWER Plant MODEL}

Recently several papers are published in which modeling methods for CHP are described, e.g. [12], [13]. However the intend of this study is to find a preferable easy and applicable model. The knowledge of the power demand of the consumers (residential neighborhood with 180 town houses) is essential for the suggested model based development. For this study the regional power supplier Süwag Renewable Energy, who is responsible for the operation of the plant, provides representative load curves for both thermal and electrical power. In the model which is set up in the simulation environment PSIM these curves are stored in ASCII files, Fig. 5.

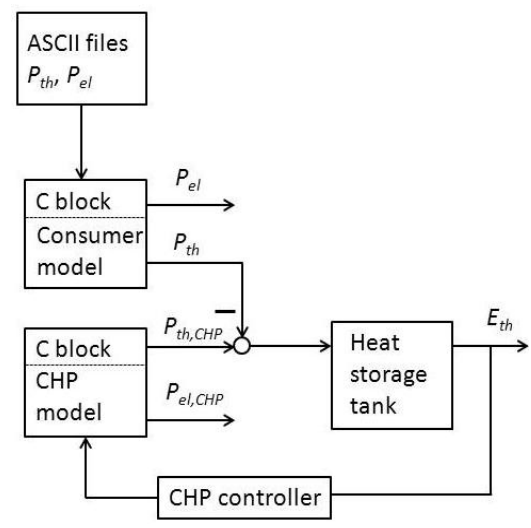

Fig. 5. Block diagram CHP model. 
In the consumer model these values are read from the ASCII files with the help of a C block and stored in two global arrays, one for the thermal and one for the electrical power. In the model the thermal power demand is transferred into a thermal power request for the thermal power management. In dependence on the capacity of the heat storage tank $E_{t h}$ the CHP is switched on and off. In the heat storage tank model the actual capacity can be easily determined by the integration of the thermal power:

$$
E_{t h}=\int\left(P_{t h, C H P}-P_{t h}\right) \cdot d t+E_{0}
$$

The initial capacity is denoted by $E_{0}$. The output of the integrator is clamped to the lower limit (zero) and the upper limit which is equal to the maximum capacity of the tank.

The electrical power demand is converted into three symmetrical sinusoidal currents. This is established in two steps. First in the $\mathrm{C}$ block the current signals (control circuit quantities) are computed in accordance to the power:

$$
P_{e l}=\sqrt{3} \cdot U \cdot I \cdot \cos \varphi
$$

$U$ is the root mean square (rms) value of the line-to-line voltage, $U=400 \mathrm{~V}$. The rms value of the phase current $I$ is calculated from Eq. 2, the momentary values of the phase currents are calculated from Eq. 3:

$$
\begin{aligned}
& i_{L 1}=\sqrt{2} \cdot I \cdot \sin (\omega t) \\
& i_{L 2}=\sqrt{2} \cdot I \cdot \sin \left(\omega t-120^{\circ}\right) \\
& i_{L 3}=\sqrt{2} \cdot I \cdot \sin \left(\omega t-240^{\circ}\right)
\end{aligned}
$$

$\omega$ is the angular frequency of the grid, $\cos \varphi$ is the power factor.

In a second step these signals are converted into currents for the low voltage network simulation (power circuit quantities), Fig. 6. In the CHP model the electrical power is determined accordant to the thermal power. Again in a $\mathrm{C}$ block, which is implemented in the CHP model, the output current signals are computed and than converted into currents for the low voltage network, Fig. 7. The utility grid is described by a symmetrical three phase $400 \mathrm{~V} / 50 \mathrm{~Hz}$ system. This is a simple but useful way to combine thermal and electric quantities in one simulation model. Fig. 8 depicts the entire model including consumer, CHP, heat storage tank and utility grid.

All electrical subsystems are connected via the three phase low voltage network. This arrangement allows an easy way to analyze the power flow.

Consumer computation

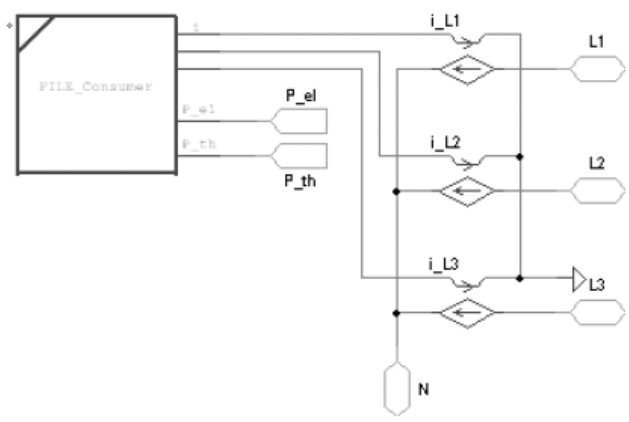

Fig. 6. Consumer model, conversion of currents.

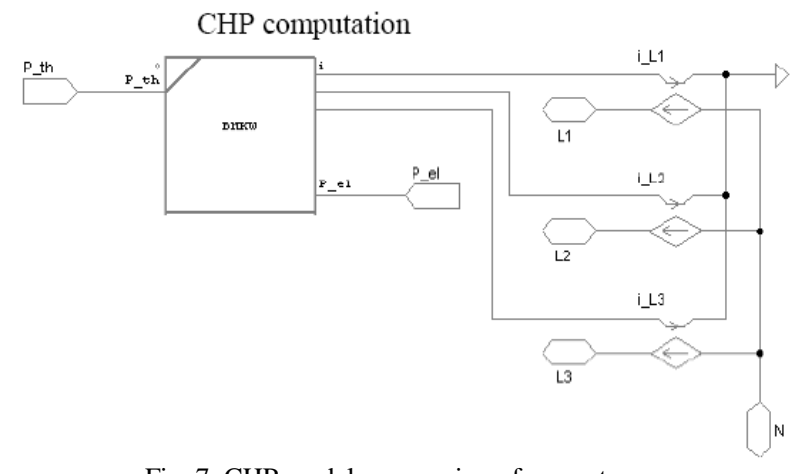

Fig. 7. CHP model, conversion of currents.

Fig. 9 shows one simulation run of a typical autumn day in Germany. The top layers indicate the electrical and thermal power demand of the town houses (consumer). The next two layers show the electrical and thermal output power of the CHP in case of an on and off operation. At this point the operation strategy of the CHP has to be analyzed with respect to the dynamic behavior, in particular the charging time of the heat tank (see Fig. 9, layer thermal capacity heat storage tank) and the temperature control. So far no optimized power management is implemented; consequently electrical power flows from the utility grid, $P_{\text {grid }}>0$. To investigate an independent power supply the PV and battery model must be integrated.

In the following two sections guidelines for this additional modeling are provided.

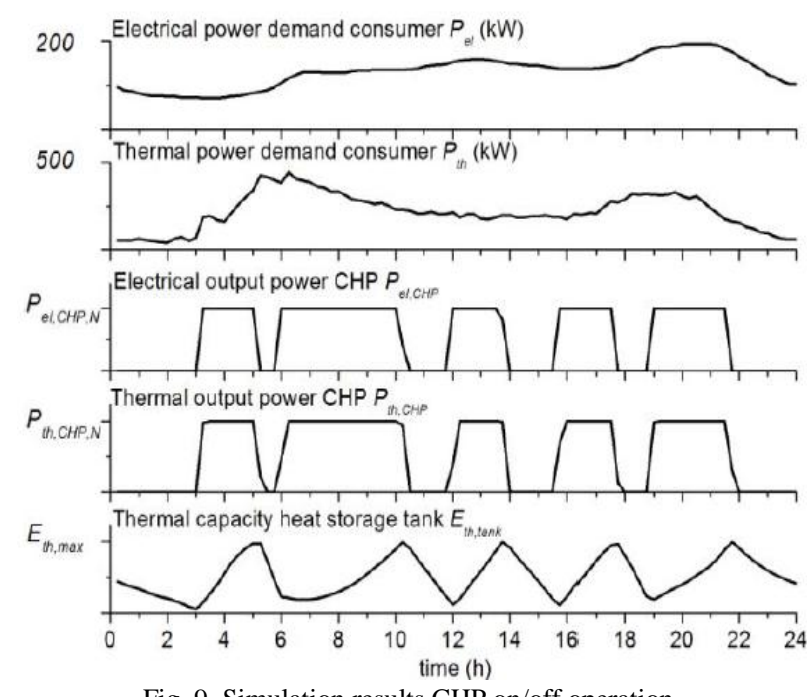

Fig. 9. Simulation results CHP on/off operation.

\section{PV MODEL}

In the presented hybrid decentralized power generation the PV modules will be installed on an anti-noise barrier which separates the housing complex from a railroad line.

The question now is how the PV system can be represented in the model. Several approaches for simulating grid connected PV systems already exist, e.g. [14], [15]. Due to its high accuracy the physical model from the PSIM library is used. With a set of parameters, which can be derived from the data sheet of the used type of solar module, the electrical behavior can be simulated in dependence on the temperature $T$ and solar irradiation $S$, Fig. 10 . 


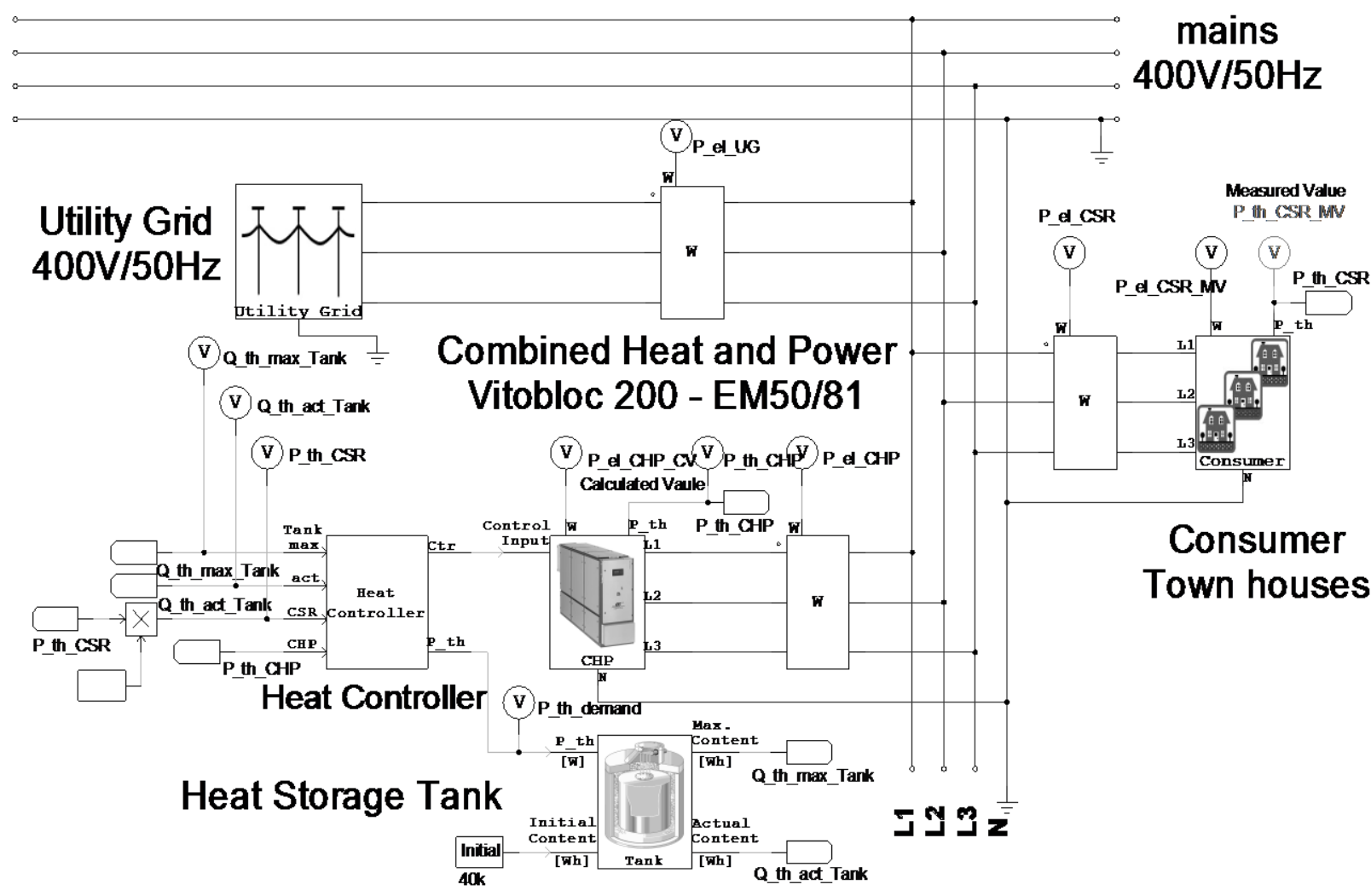

Fig. 8. PSIM simulation model of the combined heat and power plant

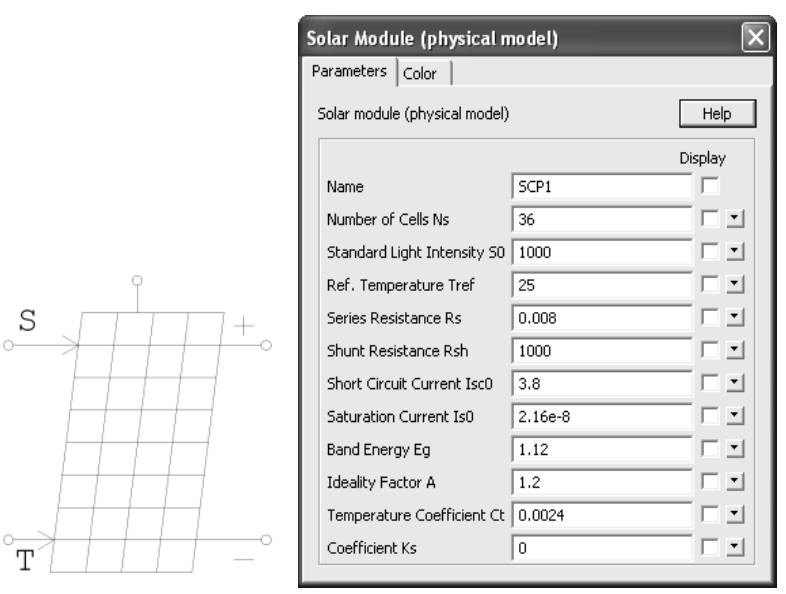

Fig. 10. PSIM parameter of the physical PV model.

As described above the output terminals of the PV array are connected to a converter (see Fig. 2). This converter consists of two power electronic components, first a boost converter which adjusts the PV array voltage $V_{D C, P V}$, second a grid-tied inverter which converts the $\mathrm{PV}$ power $P_{D C, P V}$ into the AC power $P_{A C, P V}$ for the low voltage mains, Fig. 11 and Fig. 12. Typically boost converter and inverter are switched at frequencies of several $\mathrm{kHz}$. In the proposed study it is impossible to model each switching action. Due to the high dynamic of power electronic converters the simulation of the detailed time behavior is not necessary. To meet the scope of this investigation it is only required to take the converter losses into consideration.

For example the typical inverter efficiency of a grid-tied $\mathrm{PV}$ inverter is given in Fig. 13 in dependence on the AC output power. These efficiency values can be imported into a look-up table of the inverter PSIM model. In a similar way the boost converter model can be created.

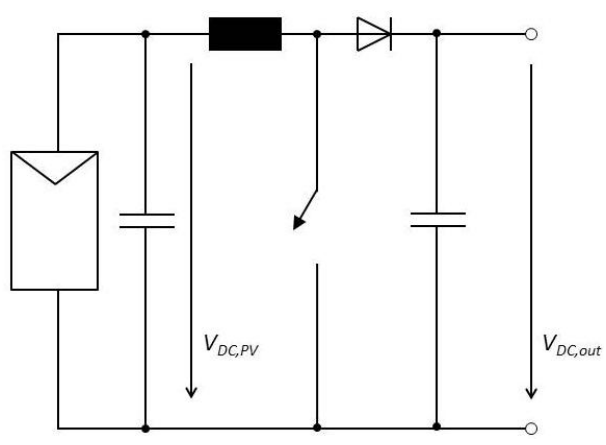

Fig. 11. Boost converter of the PV system.

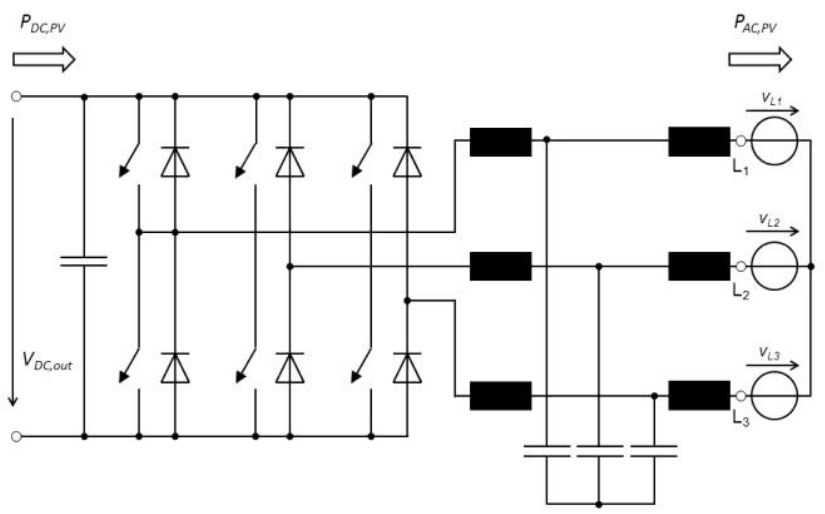

Fig. 12. Grid-tied inverter.

\section{BATTERY MODEL}

Regarding the battery modeling a large number of publications exists, e.g. [16]-[18]. Since the focus of the study is not on the investigation on the physical basics of a battery cell, the lithium-ion model of the PSIM library is used. The battery system can be described by the number of cells of the 
battery pack and specific values of the used cell type, Fig. 14. As described above the output terminals of the battery pack are connected to the input of a bidirectional converter, which consists of two power electronic components, first a bidirectional DC/DC converter as shown in Fig. 15, second a grid tied inverter with a topology as shown in Fig. 12. Similar to the modeling of the converter and inverter of the PV system it is only necessary to consider the converter losses to ensure sufficient simulation accuracy.

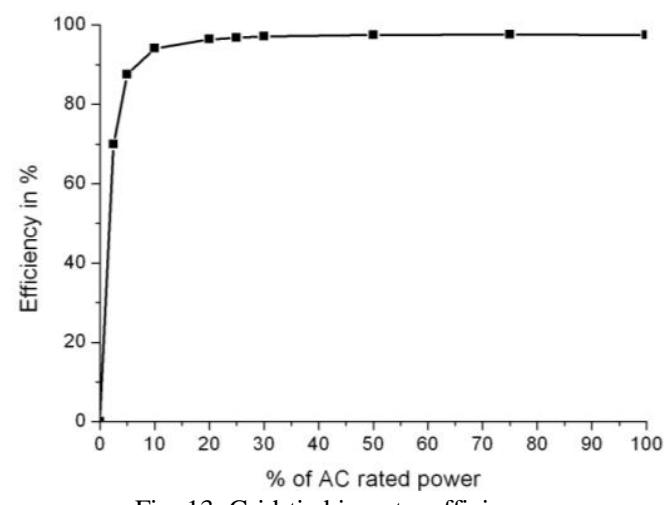

Fig. 13. Grid-tied inverter efficiency
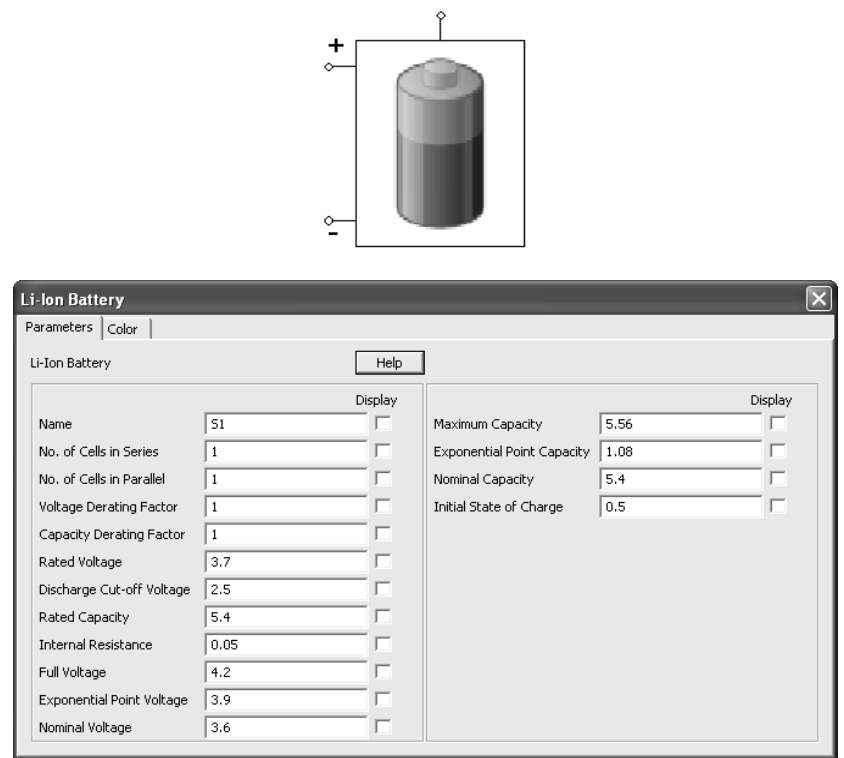

Fig. 14. PSIM parameter of the lithium-ion battery model

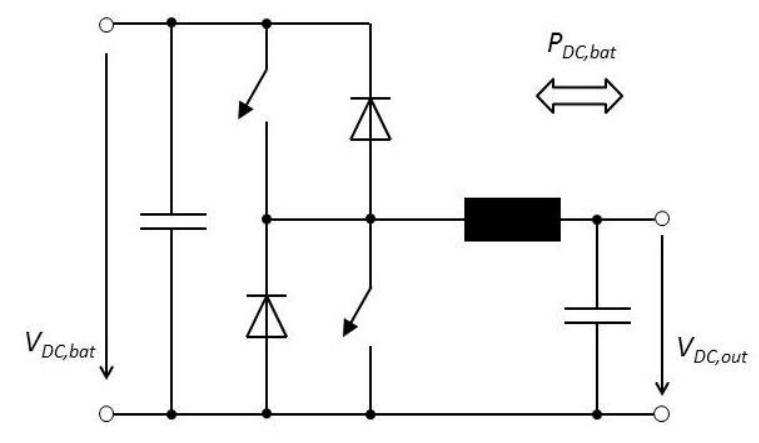

Fig. 15. Bidirectional DC/DC converter

\section{NEXT STEPS}

In the next step the models of the CHP, the heat storage tank and consumer as well as the models of the PV and battery system must be linked together. Fig. 16 shows the simplified basic control schematic of the plant. In dependence on the power demand of the consumers $P_{e l}$ and the available electrical power supplied by the CHP $P_{e l, C H P}$ the AC power $P_{A C}$ (sum of the converted DC power of the PV array and the lithium-ion battery) has to be adjusted so that the system deviation $\Delta P=P_{e l}-P_{\text {total }}$ is controlled to zero. It must be taken into account that the available battery power $P_{D C \text {,bat }}$ depends on the state of charge, the available DC power of the PV array $P_{D C, P V}$ depends on the temperature $T$ and the solar irradiation $S$. The block algorithm in Fig. 16 comprises the power management of the plant. The implementation of the algorithm in the plant operation is subject of a separate paper.

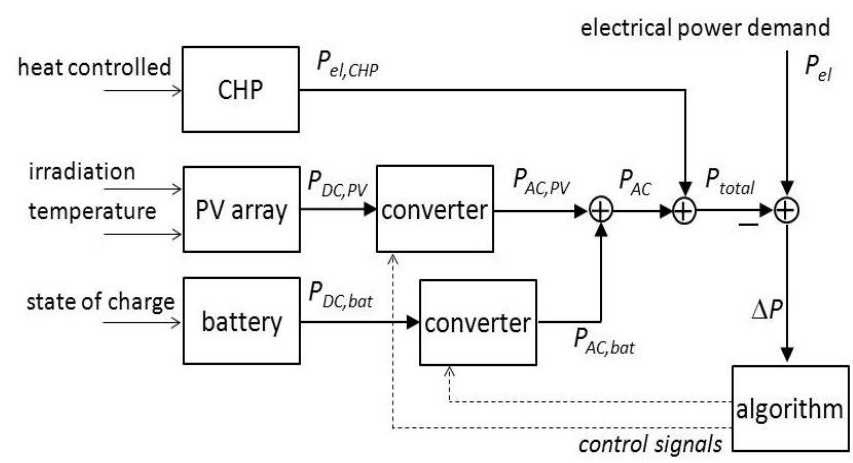

Fig. 16. Control scheme

At this time the housing complex is supplied with thermal and electrical power by the CHP only. By the end of this year the PV array and the lithium-ion battery system are installed. Once the specifications of the used PV modules and lithium-ion cells are available the optimization can be carried out. For this intent it is beneficial that several instrumentation measurements are installed in the plant. This allows the validation of the proposed models and an iterative optimization.

\section{CONCLUSION}

In this paper a forward-looking technology based on the hybrid decentralized power generation was presented. It was illustrated that a combined heat and power plant together with a photovoltaic system including a lithium-ion battery pack ensures an independent power supply. An appropriate modeling approach which enables the development of an optimized power management was explained. In particular it was demonstrated how load curves can be utilized in the model. The proposed method allows two modeling strategies. First in the load curves the thermal and electrical power demand of the residential neighborhood is stored with a sampling interval of 15 minutes. This enables the analysis of the performance of the power generation system for different seasons since the load curves can be classified into a winter, spring, summer and autumn day. Second in the load curves the power data can be stored with a higher resolution. Due to the fact that the model offers the conversion of power into currents and voltages of the mains, system perturbations can be analyzed in detail. In this way a comprehensive analysis of the operation strategy is possible.

Next year the construction work of the plant will be completed so that measurements in the final system can be 
performed. Consequently developed control algorithm based on the modeling results can be implemented and verified.

\section{ACKNOWLEDGMENT}

The author thanks the Süwag Renewable Energy GmbH in Germany for the support on this study and for the further cooperation.

\section{REFERENCES}

[1] C. Pape, S. Arbach, P. Kühn, and S. Pfaffel, "Development of wind energy in Germany," Fraunhofer IWES Kassel, June 2013.

[2] H. Wirth, "Current facts on photovoltaic in Germany," Fraunhofer ISE Freiburg, Sep. 2013.

[3] C. Naish, I. McCubbin, O. Edberg, and M. Harfoot, "Outlook of energy storage technologies," Policy Department Economy and Science, Feb. 2008.

[4] J. Vasconcelos, S. Ruesteer, X. He, E. Chong, and J. M. Glachant, "Electricity storage: how to facilitate its deployment and operation in the EU," THINK, $7^{\text {th }}$ EU Framework Program, 2012.

[5] G. Sarre, "Large scale experiments of grid connected PV systems with energy storage," presented at the $3^{\text {rd }}$ International Conference on Integration of Renewable and Distributed Energy Resources, Nice, Dec. 2008.

[6] Evonik Industries, Collaborative Research Project, LionGrid Press, Apr. 2012.

[7] C. Bendel, D. Nestle, and J. Ringelstein, "Research project DINAR," ETG Congress Karlsruhe, Oct. 2007.

[8] Solar Energy Grid Integration Systems SEGIS, Sandia National Laboratories, Oct. 2007.

[9] D. Connolly, "A review of energy storage technologies for the integration of fluctuating renewable energy," University of Limerick, August 2009.

[10] M. Bragard, N. Soltau, S. Thomas, and R. W. de Doncker, "The balance of renewable sources and user demands in grids: power electronics for modular battery energy storage systems," IEEE Transactions on Power Electronics, vol. 25, issue 12, pp. 3049-3056, Dec. 2010.

[11] R. W. de Doncker, "Towards a sustainable energy supply-the new landscape of energy technologies," Panasonic Technical Journal, vol. 57, no. 4, pp. 4-10, Jan. 2012.
[12] S. Öztürk, M. Sengül, and N. Yörükeren, "Modeling and Simulation of the Combined Heat and Power Plant of Real Industrial System," presented at the $33^{\text {rd }}$ IASTED International Conference on Modeling, Identification and Control Innsbruck, Feb. 2002.

[13] C. Schulz, G. Röder, and M. Kurrat, "Virtual power plants with combined heat and power micro-plants," presented at International Conference on Future Power Systems, Amsterdam, Nov. 2005.

[14] D. King, S. Gonzalez, and G. Galbraith, "Performance model for grid-connected photovoltaic inverters," Sandia Report, Sept. 2007.

[15] A. Ellis, "PV system models for system planning and interconnection studies," Sandia National Laboratories, Oct. 2009.

[16] H. Hongwen, R. Xiong, and J. Fan, "Evaluation of lithium-ion battery equivalent circuit models for state of charge estimation by an experimental approach," Journal Energies, vol. 4, no. 4, pp. 582-598, Mar. 2011.

[17] M. Chen and G. Ricon-Mora, "Accurate electrical battery model capable of predicting runtime and I-V performance," IEEE Transactions on Energy Conversion, vol. 21, no. 2, pp. 504-511, 2006.

[18] F. Codeca, S. Savaresi, and V. Manzoni, "The mix estimation algorithm for battery state-of-charge estimator analysis of the sensitivity to measurement errors," in Proc. 48th IEEE Conference on Decision and Control, Shanghai, P.R. China, December 2009, pp. 8083-8088.

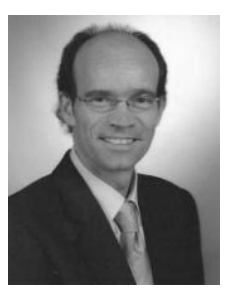

H. Hinz was born in Düren, Germany. He received the diploma degree in electrical engineering from the University of Applied Sciences, Aachen and the Ruhr University, Bochum in Germany in the years 1990 and 1994 respectively. He received the Ph.D. degree from the Technical University, Darmstadt in Germany in 2000 .

From 1999 to 2009 he worked for General Motors Europe in the research department for fuel cell vehicles. In 2009 he was appointed as a Professor for power electronics at the University of Applied Sciences, Frankfurt in Germany. Since 2011 he is the program director of the study program "Energy efficiency and renewable energy". Since 2010 he is a visiting Professor at the Vietnamese-German University in Ho-Chi-Minh City, Vietnam. His research interests are in the areas modeling, control and power electronics. 